\title{
MENINGKATKAN KREATIVITAS ANAK PRASEKOLAH DENGAN BERMAIN PLASTISIN
}

\section{INCREASING THE CREATIVITY OF CHILDREN IN PRESCHOOL BY PLASTICIN PLAYING}

\author{
Oleh: \\ M.Amin 1 , Susilawati ${ }^{2}$, dan Candra Hatta ${ }^{3}$ \\ ${ }^{1}$ Dosen Program Studi Kesehatan Masyarakat FIKES Universitas Muhammadiyah Bengkulu \\ 2,3Dosen dan Alumni Program Studi IImu Keperawatan FIKES Universitas Muhammadiyah Bengkulu \\ maminn1971@gmail.com
}

\begin{abstract}
ABSTRAK
Bermain plastisin bagian pada usia dini mempunyai banyak manfaat, salah satunya yaitu meningkatkan kreativitas anak. Tujuan penelitian ini untuk mengetahui pengaruh terapi bermain plastisin terhadap tingkat kreativitas anak prasekolah di PAUD Anak Cemerlang Kota Bengkulu. Penelitian ini menggunakan metode pre-eksperimen dengan menggunakan rancangan penelitian "one group pre test and post test design", sampel dalam penelitian ini sebanyak 15 anak, dengan pengambilan sampel secara purposive sampling. Hasil penelitian Analisis univariat menunjukkan tingkat kreativitas anak prasekolah sebelum diberikan terapi bermain plastisin 9 orang anak mulai berkembangdan 6 orang anak berkembang sesuaiharapan. Tingkat kreativitas anak setelah diberikan terapi bermain plastisin menjadi 14 orang anak berkembang sesuai harapan dan 1 orang anak berkembang sangat baik. Ratarata tingkat kreativitas sebelum diberikan terapi bermain plastisin adalah 47,83 dengan standar deviasi 4,21. Rata-rata tingkat kreativitas setelah diberikan terapi bermain plastisin terjadi peningkatan kreativitas sebesar 57,97 dengan standar deviasi 7,12. Analisis bivariat dengan uji t-dependent didapatkan $p$-value $=0,000$. Kesimpulan dalam penelitian ini ada pengaruh bermain plastisin terhadap tingkat kreativitas anak prasekolah di PAUD Anak Cemerlang Kota Bengkulu. Diharapkan pihak sekolah dapat melanjutkan bermain plastisin dengan berbagai variasi di PAUD Anak Cemerlang untuk meningkatkan kreativitas anak prasekolah.
\end{abstract}

Kata kunci :Terapi, Bermain, Plastisin, Kreativitas, prasekolah

\begin{abstract}
Playing plasticine for early childhood gives many advantages, one of which is mounting children's creativity. The purpose of this study was to find out the effect of plasticine therapeutic play on the level of creativity of preschoolers in PAUD Anak Cemerlang Bengkulu city. This study employed a preexperimental method using a research design "one group pre test and post test design". The results of this study indicate that the level of creativity of preschoolers before beingprovided therapy to play plasticine 9 children began to develop and 6 children expanded as expected. The level of children's creativity after being given therapy to play plasticine into 14 children developed according to expectations and 1 child developed very well. The average level of creativity before being given therapy to play plasticine in preschoolers in Anak Cemerlang PAUD, Bengkulu City was 47.83 with a standard deviation of 4.21. The average level of creativity after being given plasticine play therapy in preschoolers in AnakCemerlang PAUD Bengkulu City increased creativity by 57.97 with a standard deviation of 7.12. The statistical test results achieved $p$-value $=0.00$ which indicates that there is a therapeutic effect on playing plasticine on the level of creativity of preschoolers in Paud Anak Cemerlang City of Bengkulu. At last, the conclusion can be taken is that playing plasticine therapy can increase the creativity of preschoolers in AnakCemerlang PAUD Kota Bengkulu.It is expected that the school can keep on playing plasticine with its sundry variations in AnakCemerlang PAUD to rectify the creativity of preschoolers.
\end{abstract}

54 Vol. 15, No. 1, April 2020 : 1 - 73 | 


\section{Keywords: Therapy, Play, Plasticine, Creativity, Preschoolers}

\section{PENDAHULUAN}

Masa kanak-kanak merupakan masa yang sangat penting bagi perkembangan individu. Masa kanak-kanak memberi pengaruh yang besar pada individu dalam tahapan perkembangan selanjutnya. Anak prasekolah adalah anak yang berusia 3-5 tahun, yang pada umumnya kelompok anak tersebut mengikuti program sekolah seperti kelompok bermain atau playgroup dan diikuti dengan program taman kanak-kanak (Permata, 2016).

Pada masa pertumbuhan masa prasekolah pada anak pertumbuhan fisik khusunya berat badan mengalami kenaikan rata-rata pertahunnya adalah $2 \mathrm{~kg}$, kelihatan kurus akan tetapi aktivitas motorik tinggi, dimana sistem tubuh sudah mencapai kematangan seperti berjalan,melompat,dan lain-lain. Pada pertumbuhan khusunya ukuran tinggi badan anak akan bertambah rata-rata 6,75-7,5 cm setiap tahunnya. Pada masa ini anak mengalami proses perubahan dalam pola makan dimana anak pada umumnya mengalami kesulitan makan. Proses eliminasi pada anak sudah menunjukkan proses kemandirian dan masa ini adalah masa dimana perkembangan kognitif sudah mulai menunjukkan perkembangan dan anak sudah mempersiapkan diri untuk memasuki sekolah dan tampak sekali kemampuan anak belum mampu menilai sesuatu berdasarkan apa yang mereka lihat dan anak membutuhkan pengalaman belajar dengan lingkungan dan orang tua (Aziz, 2012).

Menurut Riyadi, (2013) Ciri anak prasekolah sebagai berikut : Cirifisik, penampilan anak prasekolah mudah dibedakan dengan anak yang berada pada tahapan sebelumnya. Ciri sosial, anak prasekolah biasanya mudah bersosialisasi dengan teman disekitarnya. Ciri emosional, anak prasekolah cenderung mengekpresikan emosinya dengan bebas dan terbuka. Ciri kognitif, anak prasekolah umumnya sudah terampil berbahasa, sebagian besar dari mereka senang berbicara, khusunya pada kelompoknya.

Tumbuh kembang anak usia dini meliputi beberapa aspek, salah satunya yaitu aspek fisik motorik. Fisik secara bahasa diartikan sebagai jasmani, badan, tubuh.Sedangkan motorik diartikandengan penggerak.jadi,Perkembangan fisik motorik anak usia dini dapat diartikan sebagai perubahan bentuk tubuh pada anak usia dini yang berperngaruh terhadap keterampilan gerak (Soetjiningsih, 2013).

Upaya untuk mengembangkan kreativitas anak kurang diperhatikan, akibatnya kreativitas anak kurang berkembang. Hal ini terlihat dalam rencana pembelajaran serta pelaksanaan pembelajaran dikelas. Pelaksanaan pembelajaran dikelas sangat mirip dengan pembelajaran yang terjadi di Sekolah Dasar. Akibatnya, anak kemudian menjadi bosan dan mengantuk. Anak kurang tertarik dengan pembelajaran dan sibuk dengan kegiatan sendiri. Kreativitas dan intelegensi sama-sama berperan dalam prestasi belajar. Kreativitas yang tinggi dapat meningkatkan prestasi belajar. Kreativitas sangat dibutuhkan karena banyak permasalahan serta tantangan hidup yang menuntut kemampuan adaptasi secara kreatif dalam mencari pemecahan masalah yang imajinatif (Peny, 2017).

Kreativitas adalah cara berpikir dan bertindak atau menciptakan sesuatu yang original dan bernilai / berguna bagi orang tersebut dan orang lain. Sejalan dengan yang dikemukakan oleh Gallagher mengungkapkan bahwa kreativitas berhubungan dengan kemampuan untuk menciptakan, mengadakan, menemukan suatu bentuk baru atau untuk menghasilkan sesuatu melalui keterampilan imajinatif, hal ini berarti kreativitas berhubungan dengan pengalaman mengekspresikan dan mengaktualisasikan identitas individu dalam bentuk terpadu dalam hubungan dengan diri sendiri, dengan alam dan orang lain. Oleh karena itu, kreativitas hendaknya sudah dikembangkan sedini mungkin semenjak anak dilahirkan (Masganti, 2016).

Faktor Yang Mempengaruhi Tumbuh Kembang Anak Prasekolah meliputi, faktor herideter, faktor Lingkungan, lingkungan internal, faktor pelayanan kesehatan, lingkungan eksternal, (mendongeng, menggambar, bermain alat musik sederhana, bermain Plastisin atau playdough, bermainan tulisan tempel, permainan dengan balok, perolahraga atau gerakan menari) (Aziz, 2012). 
Anak-anak pada dasarnya ingin mempelajari dan mengetahui apa saja yang dilihatnya. Dengan demikian anak bisa menyibukkan daya imajinasinya, mengembangkan kecakapan daya cipta anak. Anak-anak menjumpai mainan yang bisa dipergunakannya dengan kreatif. Misal, bermain plastisinsangat mengasyikkan. Permainan ini bisa meningkatkan kemampuan kognitif anak karena bermain plastisin membutuhkan imajinasi dan daya pikir pemainnya (Cahyo, 2011).

Bermain merupakan cara ilmiah bagi seorang anak untuk mengungkapkan konflik yang ada dalam dirinya yang ada pada awalnya anak belum sadar bahwa dirinya sedang mengalami konflik atau sebagai suatu kegiatan yang dilakukan oleh seorang anak secara sungguh-sungguh sesuai dengan keinginan sendiri/tanpa paksaan dari orang tua maupun lingkungan dimana dimaksudkan semata hanya untuk memperoleh kesenangan dan kepuasan. Dengan bermain anak dapat belajar mengungkapkan isi hati melalui kata-kata,ana kbelajar dan mamp uuntu kmenyesuaikan diri dengan lingkungannya, objek bermain, waktu ruang dan orang (Riyadi, 2013).

Menurut Ali (2015), plastisin adalah bahan terbaik yang digunakan untuk belajar dengan anak-anak karena plastisin dapat digunakan untuk mengajak dan untuk terapi.Kebanyakan anak-anak menemukan bahwa teksture dari plastisin itu sendiri yang menyenangkan untuk di sentuh dan di manipulasi atau dirubah. Ini amatlah mudah untuk membentuk sesuatu dengan plastisin dan merubahnya menjadi bentuk,ukuran, dan tampilan yang lain.Kebanyakan anak-anak telahsiapmemakaiplastisin dan mereka asik dalam perasaan, memukul-mukul plastisin, menekan plastisin, melumpuri plastisin, dan memotong plastisin.Mereka memperoleh tentang pengalaman yang menyenangkan, memuaskan. Kebanyakan, plastisin hampir seperti perluasan dari anak-anak, seperti sudah menjadi bagian dari mereka.

Manfaat Bermain Plastisin sebagai berikut: mengembangkan seni dan Kreativitas anak, mengembangkan kemampuan motorik halus anak, mengenalkan konsep warna, memperluas wawasan dan pengetahuan anak, mengembangkan imajinasi dan fantasi anak.

Berdasarkan survey dan wawancara peneliti dengan 3 orang guru di Paud Anak Cemerlang Kota Bengkulu pada tanggal 13 Februari 2019 didapatkan data bahwa jumlah guru yang mengajar di Paud Anak Cemerlang terdapat 6 orang guru beserta kepala sekolah, dan jumlah anak prasekolah yang berusia (3-4 tahun) berjumlah 20 siswa. Anak prasekolah di Paud Anak Cemerlang berada di kelas kelompok bermain (kober) dan Tk A dengan ideal guru yang mengajar yaitu 1 guru 15 anak. Permainan yang biasa digunakan oleh Paud seperti, mewarnai gambar, menggunting kertas dan menyusun puzzle, sedangkan bermain plastisin masih sedikit digunakan di Paud Anak Cemerlang karena jumlah plastisin yang masih sedikit. Plastisin di Paud Anak Cemerlang sudah menjadi 1 warna yaitu coklat, dikarenakan sering di campur menjadi 1 tempat. Sedangkan dalam membuat sebuah karakter dengan menggunakan plastisin membutuhkan beberapa warna sepeti : merah, kuning, hijau, orange dan biru. Maka dari itu masih sedikit anak yang mendapatkan bermain plastisin di Paud Anak Cemerlang.

Berdasarkan uraian diatas maka peneliti teratik untuk melakukan penelitian tentang "Pengaruh Terapi Bermain Plastisin Terhadap tingkat Kreativitas Anak Prasekolah Di Paud Anak Cemerlang Kota Bengkulu"

Penelitian ini berguna untuk member pengaruh terapi bermain plastisin terhadap tingkat kreativitas anak prasekolah, sehingga tujuan dalam penelitian ini adalah untuk mengetahui pengaruh terapi bermain plastisin terhadap tingkat kreativitas anak prasekolah di Paud Anak Cemerlang Kota Bengkulu.

\section{METODE PENELITIAN}

Jenis penelitian ini adalah penelitian kuantitatif menggunakan metode pre-ekperimen dengan rancangan one group pre test and post test design

Sampel dalam penelitian ini sebanyak 15 respondendenganteknik pengambilan sampel purposive sampling, dengan kriteria inklusi yaitu 
anakprasekolah yang berusia 3-4 tahun, tidakdalamkeadaansakit, orang tua dan anak bersedia menja diresponden

Pelaksanaan penelitian dilakukan untuk mengukur tingkat kreativitas menggunakan lembar observasi dari Kurnia Septiani (2016). dengan dua (2) kali pengukuran yaitu pengukuran pertama sebelum diberikan terapi bermain plastisin, peneliti terlebih dahulu melakukan pengukuran tingkat kreativitas menggunakan lembar observasi, setelah itu peneliti memberikan terapi bermain plastisin selama 30 menit masing-masing intervensi selama 2 minggu dengan 6 kali waktu pertemuan. Pengukuran ke II dilakukan setelah diberikan terapi bermain plastisin, pada pertemuan ke enam, peneliti kembali memberikan lembar observasi.

Setelah dilakukan pengukuran tingkatkreativitasanak dilakukan pengujian kenormalan data, yang didapatkan bahwa data berdistribusi normal sehingga dilakukan $U j i T$ dependent untuk mendapatkan nilai $p$ value.

\section{HASIL PENELITIAN}

Analisa Univariat

Tabel 1. Distribusi Frekuensi Tingkat Kreativitas Pada Anak Prasekolah Sebelum Diberikan Terapi Bermain Plastisin Di Paud Anak Cemerlang Kota Bengkulu

\begin{tabular}{|l|l|c|c|}
\hline No & Tingkat Kreativitas & $\begin{array}{c}\text { Frekuensi } \\
(\mathrm{f})\end{array}$ & $\begin{array}{c}\text { Persentase } \\
(\%)\end{array}$ \\
\hline 1 & Belum Berkembang & 0 & 0.0 \\
\hline 2 & Mulai Berkembang & 9 & 60.0 \\
\hline 3 & Berkembang Sesuai Harapan & 6 & 40.0 \\
4 & Berkembang sangat Baik & 0 & 0.0 \\
\hline & Total & 15 & 100.0 \\
\hline
\end{tabular}

Sumber: Data Primer yang sudah diolah (2019)

Berdasarkan Tabel 1 dapat diketahui berkembang dan 6responden (40\%) berkembang bahwa tingkat kreativitas anak pra sekolah sesuai harapan di PAUD Anak Cemerlang Kota sebelum terapi bermain plastisin dari 15 Bengkulu responden terdapat 9responden $(60 \%)$ mulai

Tabel 2. Distribusi Frekuensi Tingkat Kreativitas Pada Anak Prasekolah Setelah Diberikan Terapi Bermain Plastisin Di Paud Anak Cemerlang Kota Bengkulu

\begin{tabular}{|l|l|c|c|}
\hline No & Tingkat Kreativitas & $\begin{array}{c}\text { Frekuensi } \\
(\mathrm{f})\end{array}$ & $\begin{array}{c}\text { Persentase } \\
(\%)\end{array}$ \\
\hline 1 & Belum Berkembang & 0 & 0.0 \\
\hline 2 & Mulai Berkembang & 0 & 0.0 \\
\hline 3 & Berkembang Sesuai Harapan & 14 & 93.3 \\
\hline 4 & Berkembang sangat Baik & 1 & 6.7 \\
\hline & Total & 15 & 100.0 \\
\hline
\end{tabular}

Sumber: Data Primer yang sudah diolah (2019)

Berdasarkan Tabel 2 dapat diketahui bahwa tingkat kreativitas anak pra sekolah setelah terapi bermain plastisin dari 15 responden terdapat 14responden $(93,3 \%)$ berkembang sesuai harapan dan 1responden $(6,7 \%)$ berkembang sangat baik di PAUD Anak Cemerlang Kota Bengkulu. 


\section{Analisa Bivariat}

Tabel 3. Pengaruh Terapi Bermain Plastisin Terhadap Tingkat Kreativitas Anak Prasekolah Di Paud Anak Cemerlang Kota Bengkulu

\begin{tabular}{|c|c|c|c|c|c|c|}
\hline Variabel & Mean & $N$ & $\begin{array}{c}\text { Std. } \\
\text { Deviation }\end{array}$ & $T$ & df & $\begin{array}{l}\text { Sig.(2) } \\
\text { tailed) }\end{array}$ \\
\hline Sebelum & 47,8333 & \multirow[t]{2}{*}{15} & 4,21166 & \multirow{2}{*}{$-6,412$} & \multirow{2}{*}{14} & \multirow[b]{2}{*}{.000} \\
\hline Setelah & 57,9733 & & 7,12916 & & & \\
\hline
\end{tabular}

Sumber: Data Primer yang sudah diolah (2019)

Berdasarkan Tabel 3 didapatkan bahwa dari ratarata tingkat kreativitas pada anak usia sekolah sebelum dilakukan bermain plastisin yaitu 47,83 (Mulai Berkembang)dengan ( $\mathrm{SD}=4.21)$, sedangkan tingkat kreativitas pada anak usia sekolah setelah dilakukan bermain plastisinyaitu

\section{PEMBAHASAN}

\section{Pembahasan Analisis Univariat}

\section{Distribusi Frekuensi Tingkat Kreativitas Anak Prasekolah Sebelum Diberikan Terapi Bermain Plastisin}

Berdasarkan hasil penelitian didapatkan bahwa dari 15 anak prasekolah sebelum diberikan terapi bermain plastisin dapat dikategorikan mulai berkembang 9 responden (60\%) dan berkembang sesuai harapan 6 responden (40\%) di Paud Anak Cemerlang Kota Bengkulu. Hal ini dikarenakan pada anak prasekolah saat peneliti melakukan instruksi, anak-anak kurang memperhatikan dan sibuk dengan aktivitas mereka masing-masing tanpa mau mendengar instruksi peneliti.

Responden yang kreativitasnya mulai berkembang sebanyak 9 orang $(60 \%)$ adalah terkait dengan pertanyaan dibawah ini, yang tidak bisa mereka lakukan, yaitu soal nomor 3 tentang anak lancar mengemukakan jawaban dalam permainan plastisin alasanya karena anak belum mau mengikuti instruksi peneliti sehingga anakanak belum memahami apa yang dibuatnya, soal nomor 4 tentang anak dapat menggunakan beberapa permainan plastisin alasanya karena anak belum bisa memadukan beberapa permainan plastisin menjadi sebuah karakter, soal nomor 7 anak mampu membentuk permainan
57.97 (Berkembang Sesuai Harapan)dengan $(S D=7.12)$. Dari hasil ujistatistik didapatkan nilaipvalue $=0,00$, makadapat disimpulkan bahwa ada pengaruhterapi bermain plastisin terhadap tingkat kreativitas anak Pra Sekolah di PAUD Anak Cemerlang Kota Bengkulu.

plastisin sesuai arahan pada pertanyaan ini beberapa anak banyak belummampu membentuk plastisin sesuai arahan dikarenakan mereka jarang bermain plastisin disekolah sebelumnya.

Hasil ini sejalan dengan penelitian Reni. P. (2015) Menyebutkan bahwa sebelum diberikan bermain plastisin anak memiliki presentase $30,21 \%$ mulai berkembang, sedangkan hasil observasi yang dilakukan sesudah diberi perlakuan dengan media plastisin anak memiliki persentase sebanyak $71,88 \%$ berkembang sangat baik.

Distribusi Frekuensi Tingkat Kreativitas Anak Prasekolah Setelah Diberikan Terapi Bermain Plastisin

Berdasarkan hasil penelitian diperoleh bahwa dari 15 anak prasekolah setelah diberikan terapi bermain plastisin, didapatkan tingkat kreativitas anak dengan kategori berkembang sesuai harapan 14 responden (93.3\%), kategori berkembang sangat baik 1 responden (6.7\%). Hasil ini menunjukkan bahwa setelah anak prasekolah mendapatkan terpai bermain plastisin terjadiperubahan pada tingkat kreativitas anak prasekolah.

Responden yang mengalami tingkat kreativitas dengan kategori berkembang sesuai harapan sebanyak 14 responden (93.3\%) adalah terkait dengan pertanyaan sebelumnya, pertanyaan soal nomor 3 anak lancar mengemukakan jawaban dalam permainan 
plastisin, anak bisa menjawab pertanyaan yang ditanyakan oleh peneliti, soal nomor 4 anak dapat menggunakan beberapa macam permainan plastisin, terlihat beberapa anak bisa memadukan beberapa permainan plastisin, soal nomor 7 anak mampu membentuk permainan plastisin sesuai arahan, anak mampu membuat plastisin sesuai arahan.

Sejalan dengan penelitian Mirna (2016) Peningkatan kreativitas dalam bermain plastisin pada siklus I menunjukkan terdapat 6 anak mulai berkembang, 8 anak berkembang sesuai harapan sedangkan pada siklus II menunjukkan kreativitas anak menunjukkan 1 anak mulai berkembang, 4 anak berkembang sesuai harapan, 9 anak berkembang dengan baik

\section{Pembahasan Analisis Bivariat}

Pengaruh Terapi Bermain Plastisin Terhadap Tingkat Kreativitas Anak Prasekolah Di Paud Anak Cemerlang Kota Bengkulu

Berdasarkan distribusi frekuensi tingkat kreativitas anak prasekolah saat sebelum dan setelah pemberian terapi bermain plastisin terlihat perubahan frekuensi dan persentase tingkat kreativitas anak. Sebelum diberikan terapi bermain plastisin, dari 15 responden didapatkan bahwa kreativitas anak mulai berkembang 9 responden $(60 \%)$, berkembang sesuai harapan 6 responden (40\%). Sedangkan setelah diberikan terapi bermain didapatkan bahwa tingkat kreativitas anak prasekolah berkembang sesuai harapan 14 responden (93.3\%), berkembang sangat baik 1 responden (6.7\%).

Responden dengan tingkat kreativitas mulai berkembang sebanyak 9 orang $(60 \%)$ mengalami peningkatan tingkat kreativitas menjadi berkembang sesuai harapan sebanyak 14 orang $(93.3 \%)$ tentang pertanyaan pada lembar observasi setelah diberikan intervensi bermain plastisin pertanyaan soal nomor 4,5 dan 6 mengalami perubahan karena setelah diberikan terpai bermain plastisin anak mampu mengikuti instruksi dan bisa menjawab pertanyaan yang peneliti Tanya pada anak prasekolah, serta anak bisa memadukan beberapa permainan plastisin menjadi sebuah karakter meskipun belum terlalu baik.

Berdasarkan skor rata-rata, diperoleh hasil bahwa rata-rata skor kreativitas pada anak prasekolah sebelum diberikan terapi bermain adalah 47,83 dan standar deviasi sebesar 4,21, sedangkan pada saat setelah diberikan terpai bermain plastisin diperoleh rata-rata skor kreativitas sebesar 57,97 dan standar deviasi sebesar 7,12. Hasil ini menunjukkan bahwa terjadi peningkatan rata-rata skor lembar observasi pada anak prasekolah saat sebelum dan setelah diberikan terpai bermain plastsisin dan deviasi antar skor juga mengalami peningkatan.

Berdasarkan hasil uji t dependent, diperoleh $t$ $=-6,41$ dan $p$-value 0,00 . Karena $p$-value $=0,00$ $<0,05$ maka dapat disimpulkan bahwa terdapat pengaruh signifikan terapi bermain plastisin terhadap tingkat kreativitas anak prasekolah di Paud Anak Cemerlang Kota Bengkulu. Pengaruh tersebut adalah anak prasekolah yang mendapatkan terapi bermain plastsisin yeng mengalami peningkatan kretaivitas setelah diberikan terapi. Hasil penelitian ini sesuai dengan penelitian Sujarwo (2014) yang menyimpulkan bahwa terdapat perbedaan signifikan mengenai kreativitas anak sebelum dan sesudah diberikan permainan plastisin.

Penelitian ini juga sejalan dengan penelitian Partiyem (2014) berdasarkan hasil penelitian kreativitas anak dengan bermain plastisin didapatkan hasil penelitian bahwa pada siklus 1 yang memperoleh nilai $B$ sebesar 37,5 dan pada siklus II meningkat menjadi 72,5 . Hal ini membuktikan bahwa dengan bermain plastisin dapat meningkatkan kreativitas anak.Hal ini juga sama dengan penelitian Muzayyinah (2015) meningkatkan kreativitas anak melalui bermain plastisin menunjukkan perkembanagn kreativitas anak meningkat secara signifikan dibandingkan sebelum diberikan tindakan bermain.

Menurut peneliti, pemberian terapi bermain plastisin membuat anak merasa senang sehingga dapat meningkatkan kreativitas anak. Menurut Riyadi (2013), melalui bermain anak dapat mengekpresikan pikiran, perasaan, fantasi serta daya kreasi dengan tetap mengembangkan kreatifitasnya dan beradaptasi lebih efektif terhadap berbagai sumber stress.

Dalam penelitian ini media yang digunakan adalah plastisin yang berlogo SNI. Menurut Ismail (2009), Penggunaan media plastisin merupakan salah satu alat yang bisa mendorong imajinasi anak. Karena melalui media plastisin ini akan membuat anak suka berkreasi sehingga dapat 
mengembangkan kreativitasnya sebab anak melakukan aktifitas eksplorasi dalam membuat berbagai bentuk model secara bebas dan spontan. Selain dapat meningkatkan kreativitas anak, media plastisin juga bermanfaat untuk membantu pengenalan warna, melenturkan otototo jari tangan. Pemanfaatan media plastisin, selain dapat meningkatkan kreativitas, anak juga dapat mendukung peningkatan kemampuan motorik halus dan kasar anak.

Berdasarkan pengamatan langsung peneliti terhadap anak prasekolah pada saat penelitian didapatkan bahwa terdapat 1 orang anak yang tingkat kreativitasnya naik sedikit dikarenakan pada saat penelitian anak tidak mau mendengar peneliti dan anak belum paham dengan permainan plastisin karena di Paud Anak Cemerlang tersebut jarang diterapkan bermain plastisin. Pada saat penelitian anak tersebut terlihat tidak mengerti atas apa yang di perintahkan. Selain itu pada saat peneliti menjelaskan permainan plastisin anak tersebut bahkan asik berkeluyuran dan tidak mau mendengar peneliti dan guru yang ada di Paud. Pada saat diberikan intervensi anak mudah mengeluh karena tidak bisa membuat karakter dari plastisin.

\section{KESIMPULAN}

Dari 15 anak prasekolah saat sebelum diberkan terapi bermain plastisin, terdapat kreativitas 9 responden $(60 \%)$ mulai berkembang sedangkan 6 responden (40\%) berkembang sesuai harapan. Setelah diberikan terapi bermain plastisin, terdapat kreativitas 14 responden $(93,3)$ berkembang sesuai harapan sedangkan 1 responden $(6,7 \%)$ berkembang sangat baik. Berdasarkan hasil uji $t$ dependent, maka dapat disimpulkan bahwa terapi bermain plastisin dapat meningkatkan kreativitas anak prasekolah di Paud Anak Cemerlang Kota Bengkulu

\section{SARAN}

Kepada pihak sekolah dapat melanjutkan bermain plastisin di Paud sebanyak 3 kali dalam 1 bulan untuk meningkatkan kreativitas anak prasekolah; Kepada peneliti lain diharapakan dapat melanjutkan penelitian ini dengan sampel yang lebih banyak lagi serta menggunakan kelompok control dan juga bias mengaplikasi dengan permainan lain yang menunjang kreativitas anak, seperti :Lego dan puzzle. Baik secara tunggal atau kombinasi agar anak tidak merasa jenuh

\section{DAFTAR PUSTAKA}

Ali, N. 2015, Perkembangan Dan Alat Permainan Edukatif Anak Usia Dini. Jogjakarta : Editie Pustaka

Aziz, A. 2012, Pengantar Ilmu Keperawatan Anak. Jakarta : Salemba Medika

Cahyo. 2011, Gudang Permainan Kreatifitas Khusus Asah Otak Kiri Anak. Jogjakarta :Flashbooks.

Kurnia, Septiani. 2016. Meningkatkan Kreativitas Anak Usia Dini Melalui Permainan Pada Kelompok B Tk Islam Al-Falah Kota Jambi. Diakses 15, Maret, 2019, dari, http://repository.fkip.unja.ac.id/search/detil/ meningkatkan $\% 20$ kreativitas $\% 20$ anak $\% 20$ usia $\% 20$ dini $\% 20$ melalui $\% 20$ permainan $\% 20$ lego $\% 20$ pada $\% 20$ kelompok $\% 20 \mathrm{~b} \% 20 \mathrm{tk} \% 2$ 0islam\%20alfalah\%20kota\%20jambi.html

Masganti. 2016. Pengembangan Kreativitas Anak Usia

Peny Husda. 2017. Pengembangan Kreativitas Anak Usia Dini Dalam Keluarga. Diakses $25 \quad$ Maret 2019 dari:http://doi.org/10.24114/jkss.f15i2.8774

Permata \& Wiwik. 2016. Status ibu dan pengaruhnya dalam kecerdasan moral anak prasekolah. Diakses 05 februari 2019 dari

:file:///C:/Users/Ari\%20jomblo\%20syelalu/D ownloads/2905-10836-1-PB\%20(1).Pdf

Riyadi. 2013, Asuhan Keperawatan Pada Anak. Jogjakarta : Graha IImu

Soetjiningsih. 2013. Tumbuh Kembang Anak. Jakarta. ECG

V. Wiratna Sujarweni, 2014. Metodelogi Penelitian Keperawatan. Jogjakarta : Gava Media 